\title{
The interaction between vaginal microbiota, cervical length, and vaginal progesterone treatment for preterm birth risk
}

Lindsay M. Kindinger ${ }^{1,2,3}$, Phillip R. Bennett ${ }^{1,2}$, Yun S Lee ${ }^{1}$, Julian R. Marchesi ${ }^{4,5,6}$, Ann Smith $^{5}$, Stefano Cacciatore ${ }^{1}$, Elaine Holmes ${ }^{4,6}$, Jeremy K. Nicholson ${ }^{4,6}$, T. G. Teoh ${ }^{1,3}$ and David A. Maclntyre ${ }^{1 *}$

\begin{abstract}
Background: Preterm birth is the primary cause of infant death worldwide. A short cervix in the second trimester of pregnancy is a risk factor for preterm birth. In specific patient cohorts, vaginal progesterone reduces this risk. Using $16 \mathrm{~S}$ rRNA gene sequencing, we undertook a prospective study in women at risk of preterm birth $(n=161)$ to assess (1) the relationship between vaginal microbiota and cervical length in the second trimester and preterm birth risk and (2) the impact of vaginal progesterone on vaginal bacterial communities in women with a short cervix.

Results: Lactobacillus iners dominance at 16 weeks of gestation was significantly associated with both a short cervix $<25 \mathrm{~mm}(n=15, P<0.05)$ and preterm birth $<34^{+0}$ weeks $(n=18 ; P<0.01 ; 69 \%$ PPV). In contrast, Lactobacillus crispatus dominance was highly predictive of term birth ( $n=127,98 \%$ PPV). Cervical shortening and preterm birth were not associated with vaginal dysbiosis. A longitudinal characterization of vaginal microbiota $(<18,22,28$, and 34 weeks $)$ was then undertaken in women receiving vaginal progesterone ( $400 \mathrm{mg} / \mathrm{OD}, n=25)$ versus controls $(n=42)$. Progesterone did not alter vaginal bacterial community structure nor reduce $L$. iners-associated preterm birth ( $<34$ weeks).

Conclusions: L. iners dominance of the vaginal microbiota at 16 weeks of gestation is a risk factor for preterm birth, whereas L. crispatus dominance is protective against preterm birth. Vaginal progesterone does not appear to impact the pregnancy vaginal microbiota. Patients and clinicians who may be concerned about "infection risk" associated with the use of a vaginal pessary during high-risk pregnancy can be reassured.
\end{abstract}

Keywords: Vaginal microbiome, Progesterone, Lactobacillus, Preterm birth, Cervical length

\section{Background}

Preterm birth before 37 weeks of gestation is now the leading cause of death among children under the age of five [1]. An estimated 15 million babies are born preterm each year, and in the USA alone, the annual healthcare costs associated with those babies that survive is in excess of $\$ 25$ billion [2]. Ascending bacterial infection from the vagina through the cervix into the uterine cavity is considered to be a major cause of spontaneous

\footnotetext{
* Correspondence: d.macintyre@imperial.ac.uk

'Imperial College Parturition Research Group, Division of the Institute of Reproductive and Developmental Biology, Department of Surgery and Cancer, Faculty of Medicine, Imperial College London, Hammersmith Campus, London W12 ONN, UK

Full list of author information is available at the end of the article
}

preterm birth [3-5]. Maternal host-vaginal microbial interactions throughout pregnancy are likely to play a fundamental role in reproductive health outcomes. Unlike other body sites where high bacterial diversity is considered beneficial to health $[6,7]$, a healthy vaginal community structure in pregnancy is dominated by only one, or a few, Lactobacillus species $[8,9]$. These species provide protection against pathobiont colonization through excretion of lactic acid and production of antimicrobial compounds [10]. Assessment of vaginal microbial community structure can be performed using a variety of next generation sequencing and PCR-based platforms. The resulting data is typically analyzed using multivariate clustering approaches that permit comparison of 
individual taxa or community compositions [11-13]. A commonly used classification scheme involves hierarchical clustering analysis of $16 \mathrm{~S}$ rRNA gene sequencing data into community state types (CSTs) as first described by Ravel and colleagues [13]. CSTs are typically dominated by one of four Lactobacillus species; Lactobacillus crispatus (CST I), Lactobacillus gasseri (CST II), Lactobacillus iners (CST III), and Lactobacillus jensenii (CST V). CST IV describes microbial communities largely devoid of Lactobacillus species and enriched mainly in anaerobic bacteria (CST IV).

The composition of vaginal CSTs appears to be influenced by endogenous hormones, fluctuating with menses [14], the use of oral contraceptives [15] and onset of menopause [16], and estrogen supplementation in postmenopausal states [17]. In pregnancy, elevated concentrations of circulating estrogen drive glycogen accumulation in the vaginal epithelium, which is broken down by host $\alpha$-amylase to complex sugar products such as maltotetraose, maltotriose, and maltose providing carbon sources preferentially utilized by Lactobacillus species [18]. This substrate availability leads to increased Lactobacillus species abundance and stability with advancing gestation and a decline in the number of women harboring microbial communities void of lactobacilli, with a dramatic change to reduced Lactobacillus dominance and increased diversity following estrogen withdrawal in the post-partum period $[8,19]$. There is an association between Lactobacillus spp. depletion and vaginal dysbiosis and poor pregnancy outcomes including preterm birth [19] and late miscarriage [20], which appears to be patient cohort dependent [9]. Thus, the interplay between hormonal and metabolic signaling at the vaginal mucosa interface may act as a protective mechanism for the immuno-modulated pregnant mother, against exposure to pathogenic bacteria [21]. This may influence not only immediate pregnancy outcomes but also longer immunological health in the neonate such as allergy and asthma [22, 23]. This vaginal dysbiosis is present in between 2 and 27\% of the population in pregnancy but does not always appear to be pathogenic $[8,24]$. Recent evidence implicates $L$. iners dominance rather than dysbiosis for preterm birth risk in pregnancy [25]. $L$. iners is a vaginal commensal that has relatively recently been shown to be associated with dysbiosis $[26,27]$ and has been suggested as marker of microbial imbalance leading to BV [28].

The cervix serves as both a mechanical and chemical barrier to ascending bacteria [29]. Premature cervical ripening, a prerequisite for the expulsion of the fetus, may be triggered by exposure of the amniotic cavity to pathogenic bacteria ascending from the vagina [30], which drives a pro-inflammatory cytokine response, triggering prostaglandin release, and untimely cervical remodeling, softening, and dilation [31]. Premature cervical ripening is detectable by transvaginal ultrasound (TVS) several weeks prior to the onset of the clinical symptoms of preterm labor. Second trimester transvaginal cervical length measurements are considered a reliable and predictive tool for preterm birth and are frequently used for preterm birth surveillance [32]. Pregnant women with a short cervix, $<25 \mathrm{~mm}$ before 24 weeks of gestation are considered at highest risk of preterm birth [33]. Early diagnosis of these pregnancies enables timely and targeted intervention by either cervical cerclage or vaginal progesterone therapy [34]. While both prevention strategies display comparable efficacy [35], progesterone supplementation is increasingly used as it negates the surgical risks associated with cerclage insertion such as maternal pyrexia, vaginal infection, bleeding, and subsequent requirement for cesarean section [36, 37] and has not been associated with any adverse neonatal effects $[38,39]$.

The mechanism of action of vaginal progesterone in the prevention of preterm birth involves its capacity to promote anti-inflammatory and pro-relaxant pathways in the uterus thereby reducing uterine contractility [4043]. Endogenous progesterone is thought to largely exert anti-inflammatory downstream effects via progesterone receptor B-dominant signaling [43] to inhibit nitric oxide, prostaglandin, and cytokine production [41, 42]. This ultimately reduces myometrial contractility thereby inhibiting premature onset of labor [40]. Progesterone also exerts a quiescent effect on the cervix by limiting prostaglandin-induced collagenous remodeling of the cervical fibroblast [44-46]. Progesterone supplementation is therefore prescribed primarily for its systemic anti-inflammatory actions to maintain myometrial and cervical quiescence in high-risk pregnancies. In clinical studies, vaginal progesterone has been shown to attenuate the rate of cervical shortening $[47,48]$, but its efficacy in preterm birth prevention is cervical-length dependent [48-51] with most benefit observed in highrisk pregnancies with a short cervix $<25 \mathrm{~mm}$ [35]. Administration of vaginal progesterone to women with a long cervix has not been shown to improve pregnancy outcome [51]. Studies on the impact of progesterone on the composition of the vagina microbiota are limited. In non-pregnant women, Borgdorff et al. [52] found that both injectable progestin contraception and combined oral contraception (progestin and estrogen) do not significantly alter vaginal microbiota, but may increase the risk of HIV transmission [53]. It is has been hypothesized that this susceptibility relates to a progesteroneinduced modulation of the local inflammatory immune response to infection or alternately thinning of the vaginal epithelial barrier [54]. The impact of vaginal progesterone pessaries on the composition of vaginal microbial 
communities in pregnancies at risk of preterm birth is unknown.

We hypothesized that progesterone supplementation would promote Lactobacillus spp. dominance and stability, given progesterone's anti-inflammatory properties, and efficacy for preterm birth prevention. We therefore undertook a prospective study in women at high-risk of preterm birth to assess (1) the relationship between vaginal microbiota in the second trimester and the risk of preterm birth and (2) the impact of vaginal progesterone therapy on the vaginal microbiota in women with a short cervix.

\section{Methods}

The study was approved by NHS National Research Ethics Service (NRES) Committee London - City and East (REC 12/LO/2003), and all participants provided written, informed consent at enrolment. A workflow of the study is provided in Additional file 1.

\section{Patient details and sample collection for cross-sectional recruitment}

To investigate the association between the vaginal microbiome, cervical length, and preterm birth outcome, a cross-sectional cohort of singleton pregnancies at higher than normal risk of preterm birth (due to a history of previous spontaneous preterm birth $<37$ weeks ${ }^{+0}$ ${ }^{\text {days }}$ ) were prospectively recruited from the preterm surveillance clinics at two tertiary London maternity units between January 2013 and August 2014. At initial attendance of preterm surveillance clinics at 16 weeks of gestation, cervico-vaginal fluid was sampled from the posterior fornix under direct visualization, using a $\mathrm{BBL}^{\mathrm{m}}$ CultureSwab $^{\text {Tw }}$ MaxV Liquid Amies swab (Becton, Dickinson and Company, Oxford, UK). The vaginal swabs were placed immediately on ice before being transferred and stored at $-80{ }^{\circ} \mathrm{C}$ within 5 min of collection. A cervical length $(\mathrm{CL})$ measurement was taken by transvaginal scan (TVS) in supine position, with an empty bladder, taking care to avoid undue pressure on the cervix. Metadata collected included gestation age at sampling, subsequent interventions for preterm birth, gestation at birth, BMI, ethnicity, and antibiotics within the week preceding sampling. Participation in this study did not influence subsequent clinical care or dictate preventative interventions (cervical cerclage or vaginal progesterone supplementation) for preterm birth risk. For the duration of the study, both units employed a policy of CL screening every 3 weeks until 25 weeks, with the indication for intervention being a $\mathrm{CL}<25 \mathrm{~mm}$ at TVS measured at $\leq 23^{+6}$ weeks gestation. In this cross-sectional arm of the study, the choice of intervention for a short cervix (cerclage or progesterone) was at the discretion of the attending clinician.

\section{Longitudinal sampling following progesterone intervention}

A longitudinal study was undertaken in a new pregnancy cohort to assess the effect of progesterone therapy on pregnancy with a short cervix. Women with a prior preterm birth $<37$ weeks were prospectively recruited from the same preterm surveillance clinics. At initial screening $\leq 18$ weeks, all women underwent vaginal swab sampling for $16 \mathrm{~S}$ rRNA gene sequencing, followed by CL measurement at TVS, as previously described. Based on CL measurement, women were then allocated into one of two groups. Women with a short cervix $<25 \mathrm{~mm}$ were treated with vaginal progesterone $400 \mathrm{mg}$ OD at night to continue until 34 completed weeks gestation. Women with a CL $\geq 25 \mathrm{~mm}$ were used as controls and did not receive progesterone or cerclage for the remainder of their pregnancy. Both progesterone and control groups were recruited at $\leq 18$ weeks, and vaginal swab samples were collected longitudinally at 22, 28, and 34 weeks of gestation.

Eligibility criteria for participation in both crosssectional and longitudinal studies included women with a singleton pregnancy and a prior spontaneous preterm birth $<37$ weeks $^{+0}$ days, who had not undergone CL screening or received either progesterone or cerclage intervention prior to recruitment. Exclusion criteria included multiple pregnancy, preterm pre-labor rupture of membranes (PPROM), iatrogenic preterm birth, HIV positive women, and women who had had sexual intercourse or vaginal bleeding in the preceding $48 \mathrm{~h}$. In the longitudinal study, any women receiving cervical cerclage in either the progesterone or control groups were excluded as this may adversely impact on vaginal microbiota [37].

\section{DNA extraction and 16S rRNA gene sequencing}

DNA extraction from $\mathrm{BBL}^{\mathrm{\tau м}}$ CultureSwab ${ }^{\text {тм }}$ was performed as previously described [8]. Forward and reverse fusion primers were used to amplify the V1-V3 hypervariable regions of $16 \mathrm{~S}$ rRNA genes. The forward primer was made up of an Illumina i5 adapter (5'-3') (AATGATACGGCGACCACCGAGATCTACAC), 8 bp barcode, primer pad (forward: TATGGTAATT), and the 28FGAGTTTGATCNTGGCTCAG primer [55]. The reverse fusion primer consisted of an (5'-3') Illumina i7 adapter (CAAGCAGAAGACGGCATACGAGAT), 8 bp barcode, primer pad (reverse: AGTCAGTCAG), and the reverse primer (519R-GTNTTACNGCGGCKGCTG). Sequencing was performed on an Illumina MiSeq platform (Illumina, Inc. San Diego, California). Sequence data was processed and analyzed using the MiSeq SOP Pipeline of the Mothur package [56] with the Silva bacterial database (www.arb-silva.de/) used for sequence alignment. Sequence classification was performed using the RDP 
database reference sequence files and the Wang method [57] and taxonomy assignments determined using the RDP MultiClassifier script and USEARCH with $16 \mathrm{~S}$ rRNA gene sequences from the cultured representatives from the RDP database [58] for species level taxonomies. Data was re-sampled and normalized to the lowest read count in Mothur $(n=725)$ [59].

\section{Statistical analyses}

Examination of statistical differences between vaginal microbiota was performed using the Statistical Analysis of Metagenomic Profiles (STAMP) software package [60]. To classify vaginal bacterial communities into community state types (CSTs), hierarchical clustering analysis (HCA) species taxonomy was performed using ward linkage with a clustering density threshold of 0.75 . Samples were classified into five CSTs; I (L. crispatus), II (L. gasseri), III (L. iners), IV (mixed bacterial species), and $\mathrm{V}($ L. jensenii) as described by Ravel et al. [13].

\section{Cross-sectional cohort}

In the cross-sectional cohort, a total number of species observed and the Shannon index of alpha diversity were calculated and compared across gestation at birth: $<34$ ${ }^{+0}$ weeks, $34^{+0}$ to $36^{+6}$ weeks, and $\geq 37^{+0}$ weeks, using a 2-way ANOVA.

Examination of the relationship between vaginal bacterial communities (or CSTs) and cervical length or preterm birth was assessed using a Fisher exact test as to provide an exact, robust $P$ value that is less sensitive to small sample sizes than alternative approaches such as Chi-squared (reference). Fisher's exact test was also used to examine individual CST assignments (in $5 \times 2$ contingency tables for cervical length and requirement for future interventions and $3 \times 25$ contingency tables for birth gestation and ethnicity). Gehan-Breslow-Wilcoxon test was used to compare pregnancy survival (duration of gestation) for CST I compared to CST III [61].

A logistic mixed-effects regression analysis incorporating gestational age at sample, maternal age, and BMI as fixed effects and ethnicity as a random effect was performed to assess the relationship between pregnancy outcome (birth $<34$ and $>34$ weeks) and CSTs as well as individual species abundance. Analyses were performed in R using ANOVA and the "glm" (generalized linear model) $\mathrm{R}$ function to analyze the table of deviance for CSTs and for individual species (present in $>5 \%$ of samples). Species abundances were log-transformed, adjusted for confounders, and false discovery rate adjustment (Benjamini-Hochberg) was applied to correct $P$ values for each analysis [62].

Accuracy parameters, sensitivity (sens), specificity (spec), positive predictive values (PPV), and negative predictive values (NPV) were calculated for the prediction of preterm birth $<34^{+0}$ weeks according to CST classification at 16-week sampling.

\section{Longitudinal cohort}

A linear mixed-effects model incorporating gestational age, maternal age, BMI, ethnicity (Asian, Black, or Caucasian), and cohort (progesterone with short cervix versus control with normal cervix) as fixed-effects and the anonymized patient ID as uncorrelated random-effect was used to assess the impact of progesterone intervention on CST distribution and relative abundance in species present in $>5 \%$ of all samples. The contributions of fixed-effects terms ( $P$ value and $F$ statistics) were calculated using ANOVA with Satterthwaite approximation for degrees of freedom. For each fixed-effects term, a false discovery rate adjustment (Benjamin-Hochberg) was applied to correct $P$ values. All data and computational approaches used for this study are provided in additional information (Additional files 2, 3, 4, 5, and 6).

\section{Results}

Cross-sectional study patient cohort demographics

A total of 161 pregnant women attending prematurity surveillance clinics for their first appointment (mean 16 ${ }^{+6}$ weeks gestation, Table 1) consented to a vaginal swab followed by a transvaginal scan for cervical length measurement. Spontaneous preterm birth $<37$ weeks occurred in 34 women $(21 \%)$ (mean $32^{+6}$ weeks, $\mathrm{SD} \pm 3$ ${ }^{+6}$ weeks, range $24^{+4}-36^{+6}$ weeks). Rates of preterm birth $<37^{+0}$ weeks were higher in Black women $(37 \%, 11 / 30)$ than Caucasians $(17 \%, 18 / 104)$ and Asians $(19 \%, 5 / 27 ; P$ $<0.05)$. Subsequent cervical shortening to below $25 \mathrm{~mm}$ occurred in $66 \%$ (91/161), all of whom went on to receive an intervention (ultrasound indicated cervical cerclage, $n=71$ or vaginal progesterone, $n=20$ ).

\section{The vaginal microbiome at 16 weeks in high-risk pregnancy}

Using hierarchical clustering analysis (HCA) of normalized genera taxonomy read counts, vaginal swab samples were classified into three categories; normal (>90\% Lactobacillus spp., 147/161, 91\%), intermediate (50-90\% Lactobacillus spp., 5/161, 3\%), and dysbiotic $(<10 \%$ Lactobacillus spp., 9/161, 6\%; Additional file 7A). No relationship was observed between genera level structure and subsequent gestational age at delivery. Dominance of Lactobacillus species occurred in equal proportions of patients experiencing preterm <37 weeks $(31 / 34 ; 91 \%)$ or term birth (116/127; 91\%). Of those women delivering preterm, 3/34 (9\%) harbored a dysbiotic or intermediate microbiome at 16 weeks compared to $6 / 127$ (5\%) who delivered at term. Consistent with these findings, measurements of species richness (total number of species observed; Additional file 7B) and alpha diversity 
Table 1 Patient demographics for a cross-section of 161 participants

\begin{tabular}{|c|c|c|c|}
\hline & Term birth $>37$ weeks & Preterm birth <37 weeks & Total \\
\hline$n / N(\%)$ & 127/161 (79\%) & $34 / 161$ (21\%) & $161 / 161(100 \%)$ \\
\hline \multicolumn{4}{|l|}{ BMI } \\
\hline Mean \pm SD (range) & $24.3 \pm 4.4(18-48)$ & $24.3 \pm 4.4(18.4-35)$ & $24.3 \pm 4.4(18-48)$ \\
\hline \multicolumn{4}{|l|}{ Ethnicity, $n / N(\%)$} \\
\hline Caucasian & $86 / 127(68 \%)$ & 18/34 (53\%) & 104/161 (65\%) \\
\hline Asian & $22 / 127(17 \%)$ & $5 / 34(15 \%)$ & $27 / 161(17 \%)$ \\
\hline Black & 19/127 (15\%) & $11 / 34(32 \%)^{*}$ & $30 / 161$ (19\%) \\
\hline Smoker, n/N (\%) & $8 / 127(6 \%)$ & $3 / 34(9 \%)$ & $11 / 161(7 \%)$ \\
\hline \multicolumn{4}{|l|}{ Gestation at sample (weeks) } \\
\hline Mean \pm SD (range) & $17^{+0} \pm 1.0\left(13^{+1}-18^{+4}\right)$ & $16^{+4} \pm 1.4\left(12^{+1}-18^{+4}\right)$ & $16^{+6} \pm 1.1\left(12^{+1}-18^{+4}\right)$ \\
\hline \multicolumn{4}{|l|}{ Cervical length (mm) } \\
\hline Mean \pm SD (range) & $32.5 \pm 1.0(18-50)$ & $30.6 \pm 6.4(10-40)$ & $32 \pm 5.6(10-50)$ \\
\hline \multicolumn{4}{|l|}{ Intervention n/N (\%) } \\
\hline No intervention & $60 / 127(47 \%)$ & 10/32 (29\%) & 70/161 (43\%) \\
\hline Cerclage & $51 / 127(40 \%)$ & 20/32 (59\%) & 71/161 (44\%) \\
\hline Progesterone & 16/127 (13\%) & $4 / 32(12 \%)$ & 20/161 (12\%) \\
\hline \multicolumn{4}{|l|}{ Gestation at delivery, $n / N(\%)$} \\
\hline Early PTB, $<34^{+0}$ weeks & na & 18/34 (53\%) & 18/161 (11\%) \\
\hline Late PTB, $34^{+0}$ to $<37^{+0}$ weeks & na & $16 / 34(47 \%)$ & 16/161 (10\%) \\
\hline Term, $\geq 37^{+0}$ weeks & $127 / 127(100 \%)$ & na & 127/161 (79\%) \\
\hline
\end{tabular}

PTB preterm birth, na not applicable

${ }^{*} P<0.05$ Fisher's exact term vs. preterm birth groups

(Shannon index; Additional file 7C) at 16 weeks were comparable between women experiencing term $\left(\geq 37^{+0}\right.$ weeks, $n=127)$, late preterm $\left(34^{+0}-36^{+6}\right.$ weeks, $\left.n=16\right)$, and early preterm $\left(<34^{+0}\right.$ weeks, $\left.n=18\right)$ delivery.

Hierarchical clustering of species data permitted classification of samples into community state types (CSTs): I (L. crispatus), II (L. gasseri), III (L. iners), IV (diverse species), and V (L. jensenii) (Fig. 1a). The most prevalent CST observed in the patient cohort was CST I (L. crispatus, $40 \%$ ), followed by CST III, (L. iners, 34\%), CST II (L. gasseri, 10\%); CST V (L. jensenii, 9\%), and CST IV (diverse, 6\%; Table 2). L. crispatus (CST I) was most abundant among Caucasian women $(P=0.008)$, while Black women had greater numbers of CST III ( $L$. iners; $P=0.049$ and CST IV $(P=0.033)$ (Fisher's exact, Table 2$)$. Short CL $<25 \mathrm{~mm}$ was significantly associated with $L$. iners (CST III) dominance $(9 / 15,60 \%)$ compared to those women with a CL $>25 \mathrm{~mm}(45 / 101,31 \% ; P=0.04$; Fisher's exact, Fig. 1b).

The association of the vaginal microbiome at 16 weeks of gestation and risk of preterm birth

Major differences were detected in vaginal microbial communities at 16 weeks in women subsequently delivering early preterm $\left(<34^{+0}\right.$ weeks $)$ compared those delivering late preterm $\left(34^{+0}\right.$ to $36^{+6}$ weeks $)$ or at term $\left(>37^{+0}\right.$ weeks) (Fig. 1b, Table 2). Specifically, an L. inersdominated microbiome was significantly overrepresented in women delivering $<34^{+0}$ weeks $(67 \%)$ compared to late preterm $(31 \%)$ and term $(29 \% ; P=$ 0.003 , Fisher's exact). In contrast, $L$. crispatus dominance associated with subsequent term birth (46 vs. $11 \%$ early preterm birth; $P=0.009$, Fisher's exact, Fig. 1c, Table 2), and comparatively longer duration of pregnancy than $L$. iners Fig. 1d. A logistic regression mixed-effects model demonstrated that the association between gestation at birth and CST at 16 weeks persisted after accounting for ethnicity, maternal age, BMI, and gestation at sampling $(P=0.04$; ANOVA; Additional file 8$)$. When individual species were assessed by mixed-effects modeling following correction for potential confounders, both $L$. crispatus and $L$. iners were significantly correlated with birth outcome with $L$. crispatus positively associated with delivery $>34$ weeks $(P=0.009, q=0.048)$ and $L$. iners positively associated with delivery $<34$ weeks $(P=0.001$, $q=0.006$; Additional file 9).

The analysis of outcomes stratified by ethnicity did not identify a significant difference between groups although this may be due to relatively small sample sizes. The majority of women delivering $>34$ weeks with $L$. crispatus dominance (CST I) were Caucasian (Caucasian 50/95, $53 \%$, Asian 7/23, 30\%, and Black women 6/25, 24\%), but 


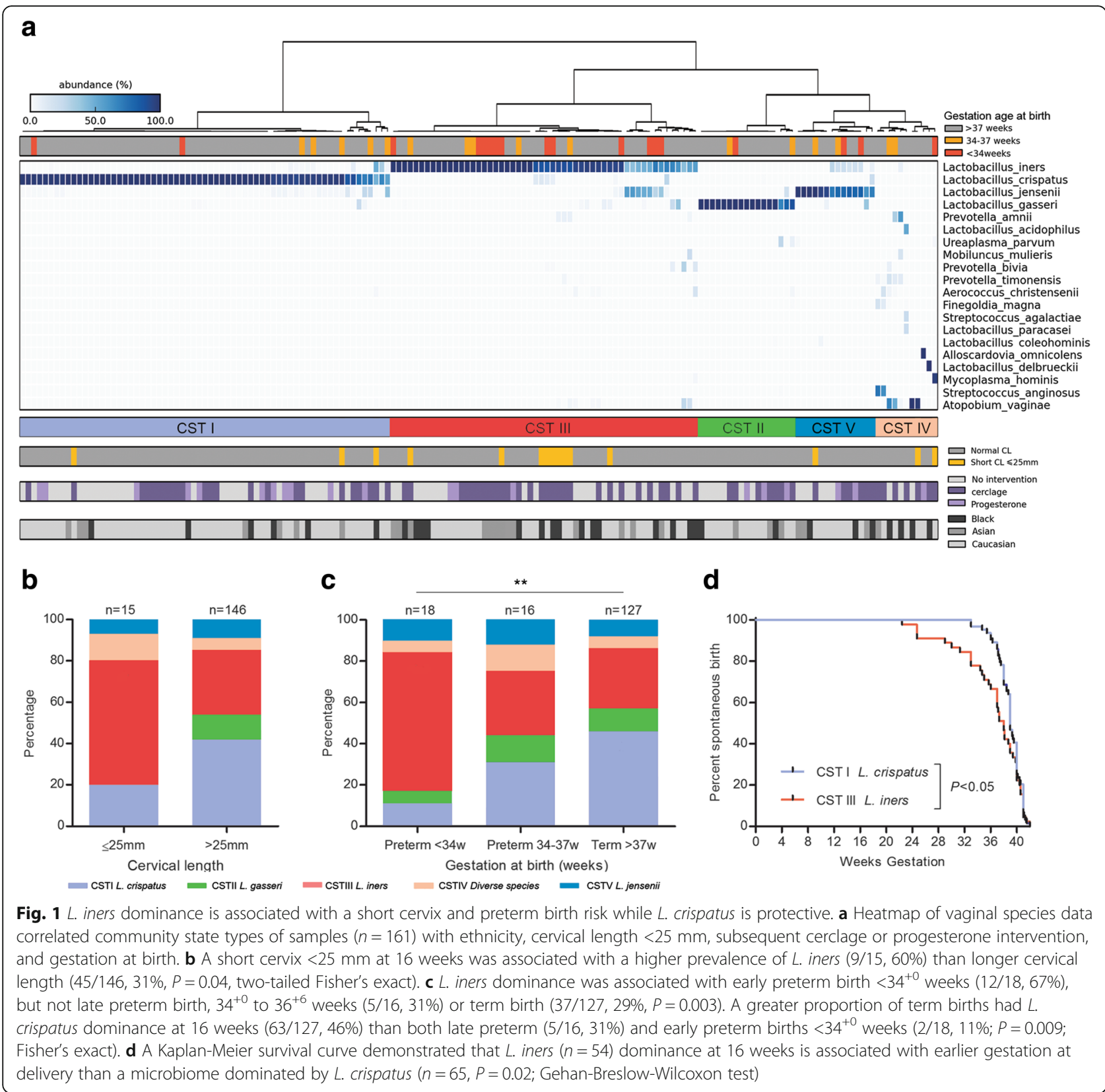

this was not significant. In those women delivering $<34$ with $L$. iners dominance (CST III), similar proportions were represented across ethnic groups (Caucasian 6/9, $67 \%$, Asian 3/4, 75\%, and Black women 3/5, 60\%; Additional file 10).

Calculation of predictive accuracies for preterm birth using CST assignments at 16 weeks provided sensitivity and specificity values comparable to screening using cervical length [32]: $L$. iners dominance predicted preterm birth $<34^{+0}$ weeks with $67 \%$ sensitivity and $71 \%$ specificity (Table 3 ). While its absence provided a $94 \%$ negative predictive value (NPV), the PPV of $L$. iners dominance for preterm birth $<34$ weeks was $22 \%$. High relative $L$. crispatus abundance was strongly predictive of birth $>34$ weeks gestation (89\% specificity and 97\% PPV; Table 3).

Effect of progesterone intervention on vaginal microbial communities in high-risk pregnancy

Given the significant association between vaginal microbial composition at 16 weeks and cervical length and/or subsequent preterm birth $<34^{+0}$ weeks, we next conducted a longitudinal study of the vaginal microbiome in women receiving vaginal progesterone supplementation for a short cervix $(<25 \mathrm{~mm})$. A total of 67 pregnant women were eligible and consented to recruitment, of 
Table 2 Distribution of community state types according to ethnicity and gestation at birth

\begin{tabular}{|c|c|c|c|c|c|c|c|c|c|c|c|c|}
\hline \multirow[b]{3}{*}{$n / N(\%)$} & & & \multicolumn{10}{|c|}{ CST, Species } \\
\hline & \multicolumn{2}{|c|}{ Total population } & \multicolumn{2}{|c|}{ CST I, L. crispatus } & \multicolumn{2}{|c|}{ CST II, L. gasseri } & \multicolumn{2}{|c|}{ CST III, L. iners } & \multicolumn{2}{|c|}{ CST IV, diverse species } & \multicolumn{2}{|c|}{ CST V, L. jensenii } \\
\hline & 161 & $(100 \%)$ & $65 / 161$ & $(40 \%)$ & $17 / 161$ & $(11 \%)$ & $54 / 161$ & (34\%) & $11 / 161$ & $(7 \%)$ & $14 / 161$ & (9\%) \\
\hline \multicolumn{13}{|l|}{ Ethnicity } \\
\hline Caucasian & $104 / 161$ & $(65 \%)$ & $52 / 104$ & $(50 \%)^{*}$ & $13 / 104$ & $(13 \%)$ & $26 / 104$ & $(25 \%)$ & $5 / 104$ & $(5 \%)$ & $8 / 104$ & (8\%) \\
\hline Asian & $27 / 161$ & $(17 \%)$ & $7 / 27$ & $(26 \%)$ & $3 / 27$ & $(11 \%)$ & $13 / 27$ & $(48 \%)^{*}$ & $1 / 27$ & $(4 \%)$ & $3 / 27$ & $(11 \%)$ \\
\hline Black & $30 / 161$ & $(19 \%)$ & $6 / 30$ & $(20 \%)$ & $1 / 30$ & (3\%) & $15 / 30$ & $(50 \%)^{*}$ & $5 / 30$ & $(17 \%)^{*}$ & $3 / 30$ & $(10 \%)$ \\
\hline \multicolumn{13}{|l|}{ Gestation at birth } \\
\hline$<34$ weeks & $18 / 161$ & $(11 \%)$ & $2 / 18$ & $(11 \%)^{* *}$ & $1 / 18$ & $(6 \%)$ & $12 / 18$ & $(67 \%)^{* *}$ & $1 / 18$ & $(6 \%)$ & $2 / 18$ & $(11 \%)$ \\
\hline 34-37 weeks & $16 / 161$ & $(10 \%)$ & $5 / 16$ & $(31 \%)$ & $2 / 16$ & $(13 \%)$ & $5 / 16$ & $(31 \%)$ & $2 / 16$ & $(13 \%)$ & $2 / 16$ & $(13 \%)$ \\
\hline$>37$ weeks & $127 / 161$ & (79\%) & $58 / 127$ & $(46 \%)$ & $14 / 127$ & $(11 \%)$ & $37 / 127$ & $(29 \%)$ & $8 / 127$ & $(6 \%)$ & $10 / 127$ & (8\%) \\
\hline
\end{tabular}

CST community state type based on ward HCA of species data

${ }^{*} P<0.05$, ${ }^{* *} P<0.01$; for comparison of birth $<34$ vs. $>34$ weeks, two-tailed Fisher's exact

which 25 were found to have a short $\mathrm{CL}<25 \mathrm{~mm}$ and received progesterone until 34 weeks of gestation. The remaining 42 women did not experience cervical shortening or receive any subsequent preventative intervention, and hence were used as controls. Demographics of the two groups were comparable although, as per study design, the mean $\mathrm{CL}$ at commencement of progesterone was significantly lower in the "short CL" than the "normal" control group ( 22 vs. $32 \mathrm{~mm}, P<0.05)$ at comparable screening gestations $\left(15^{+5}\right.$ vs. $15^{+0}$, respectively; Table 4). Respective rates of preterm birth ( $<37$ weeks) were higher in the progesterone $(32 \%, 8 / 25)$ versus control groups $(5 \%, 2 / 42 ; P=0.004)$. A total of 234 high vaginal samples were collected from longitudinal followup $(22,28$, and 34 weeks) at matched gestational ages among groups (Additional file 11).

The distribution of CSTs in the progesterone and control groups at each sampling time point is provided in Additional file 12. Prior to progesterone intervention, no significant difference in the distribution of CSTs between to the two patient cohorts was observed (Fig. 2; Additional file 12). Vaginal progesterone supplementation had no effect upon vaginal bacterial community state structure throughout pregnancy (Fig. 2a) nor were species richness or alpha diversity measurements altered (Fig. 2b, c). Progesterone supplementation did not significantly impact on mean relative abundance of $L$. iners or L. crispatus with advancing gestation when compared to controls (Fig. 2d, c; Additional file 13).

The dynamics of individual vaginal CSTs during pregnancy were then longitudinally assessed in both progesterone and control cohorts (Fig. 3). Regardless of intervention, a $L$. crispatus (CST I)-dominated microbiome was associated with high stability throughout pregnancy with $92 \%(24 / 26)$ of women maintaining $L$. crispatus dominance across all sampling time points. In contrast, significantly lower stability was observed in the 23 women exhibiting a $L$. iners-dominated microbiome at the first sampling with $17(74 \%)$ of these women experiencing a shift to an alternative CST at some stage during their pregnancy $(P<0.0001)$. Similar levels of CST-shifting were observed in those women receiving vaginal supplementation $(9 / 25 ; 36 \%)$ and control patients $(10 / 43 ; 23 \%)(P=0.3)$.

When gestational age at sampling, maternal age, BMI, ethnicity, and cohort were incorporated into a linear mixed-effects model, progesterone treatment did not have a significant impact upon CSTs apart from CST II; however, this difference did not withstand multiple testing correction (Additional file 14). When further assessed by relative abundance of individual species, there were no significant differences in proportions of $L$. gasseri, or any other species in the control compared to progesterone cohorts (Additional file 15).

Table 3 Predictive accuracies of microbial species dominance at 16 weeks for gestation $<34$ weeks

\begin{tabular}{|c|c|c|c|c|c|c|c|c|c|}
\hline \multirow[t]{2}{*}{ CST } & \multirow[t]{2}{*}{ Species } & \multicolumn{4}{|c|}{ Preterm birth <34 weeks } & \multicolumn{4}{|c|}{ Birth $>34$ weeks } \\
\hline & & Sens/DR (\%) & Spec (\%) & PPV (\%) & NPV (\%) & Sens/DR (\%) & Spec (\%) & PPV (\%) & NPV (\%) \\
\hline । & L. crispatus & 11 & 56 & 3 & 83 & 44 & 89 & 97 & 17 \\
\hline$\|$ & L. gasseri & 6 & 89 & 6 & 88 & 11 & 94 & 94 & 12 \\
\hline III & L. iners & 67 & 71 & 22 & 94 & 29 & 33 & 78 & 6 \\
\hline IV & Diverse & 6 & 93 & 9 & 89 & 7 & 94 & 91 & 11 \\
\hline V & L. jensenii & 11 & 92 & 14 & 89 & 8 & 89 & 86 & 11 \\
\hline
\end{tabular}

CST community state type based on ward HCA of species data, Sens/DR sensitivity or detection rate, Spec specificity, PPV/NPV positive/negative predictive values 
Table 4 Participant demographics for control and progesterone groups

\begin{tabular}{|c|c|c|c|}
\hline & High risk controls & Progesterone & Total \\
\hline$n / N(\%)$ & $42 / 67(63 \%)$ & $25 / 67(37 \%)$ & $67 / 67(100 \%)$ \\
\hline \multicolumn{4}{|l|}{ Age, years } \\
\hline Mean \pm SD (range) & $32 \pm 5.5(21-40)$ & $32 \pm 3.9(22-38)$ & $32 \pm 5.0(21-40)$ \\
\hline \multicolumn{4}{|l|}{ BMl } \\
\hline Mean \pm SD (range) & $24.7 \pm 5.3(19-48)$ & $25.2 \pm 4.7(18.4-35)$ & $24.9 \pm 5.0(18.4-48$ \\
\hline \multicolumn{4}{|l|}{ Ethnicity, n/N (\%) } \\
\hline Caucasian & $32 / 42(76 \%)$ & $18 / 25(72 \%)$ & $50 / 67(75 \%)$ \\
\hline Asian & $4 / 42(10 \%)$ & $3 / 25(12 \%)$ & $7 / 67(10 \%)$ \\
\hline Black & $6 / 42(14 \%)$ & $4 / 25(16 \%)$ & 10/67 (15\%) \\
\hline Smoker n/N (\%) & $2 / 42(5 \%)$ & $0 / 25(0 \%)$ & $2 / 67(3 \%)$ \\
\hline \multicolumn{4}{|l|}{ Screening for progesterone } \\
\hline GA (weeks), median, range & $15^{+0}\left(12^{+1}-18^{+2}\right)$ & $15^{+6}\left(12^{+0}-18^{+6}\right)$ & $15^{+3}\left(12^{+0}-18^{+6}\right)$ \\
\hline $\mathrm{CL}(\mathrm{mm})$, median, range & $32(26-43)$ & $22(13-25)$ & $(13-43)$ \\
\hline \multicolumn{4}{|l|}{ Gestation at delivery, n/N (\%) } \\
\hline Early PTB, $<34^{+0}$ weeks & $1 / 42(2 \%)$ & $4 / 25(16 \%)$ & $5 / 67(7 \%)$ \\
\hline Late PTB, $34^{+0}$ to $<37^{+0}$ weeks & $1 / 42(2 \%)$ & $4 / 25(16 \%)$ & $5 / 67(7 \%)$ \\
\hline Term, $\geq 37^{+0}$ weeks & 40/42 (95\%) & $17 / 25(68 \%)$ & $57 / 67(85 \%)$ \\
\hline
\end{tabular}

PTB preterm birth, GA gestational age, $C L$ cervical length $(\mathrm{mm})$

In women receiving progesterone, marked differences in the longitudinal CST distributions were observed in women delivering $<34$ weeks compared to those delivering $>34$ weeks (Fig. 4). At 18 weeks of gestation, $L$. iners dominance was observed in $100 \%(4 / 4)$ of women who subsequently delivered $<34$ weeks of gestation compared to $24 \%(5 / 21)$ in women delivering $>34$ weeks. At delivery, $L$. iners dominance was observed in $50 \%(2 / 4)$ at 22 weeks and $100 \%(4 / 4)$ at 28 weeks (Figs. 3 and 4).

\section{Discussion}

This study represents the largest next generation sequencing-based analysis of vaginal microbiota in pregnancies at risk of preterm birth to date. We demonstrate a significant association between $L$. iners dominance of the vaginal microbiome at 16 weeks of gestation with subsequent preterm birth and conversely show that $L$. crispatus dominance correlates with reduced risk or preterm birth. Moreover, we show that the insertion of a progesterone pessary for prevention of preterm birth has no adverse impact on vaginal microbial communities.

A healthy vaginal microbiome in non-gravid and gravid subjects is often described as being synonymous with low bacterial diversity and Lactobacillus species dominance [63-66]. Examination of vaginal microbiota at the time of delivery using culture and/or microscopybased techniques has shown that Lactobacillus species dominance is negatively associated with delivery before 37 weeks of gestation (odds ratio 0.2) whereas bacterial dysbiosis is positively associated with preterm delivery (odds ratio 2.3) [66]. Using similar methodology, Donders and colleagues recently reported that a lactobacilli-dominated vaginal microbiome in the first trimester was associated with a $75 \%$ lower risk of delivery before 35 weeks of gestation $(0.26$; $95 \%$ confidence interval (CI) 0.12-0.56] compared to women harboring a vaginal microbiome void of Lactobacillus species (OR 2.4; 95\% CI 1.2-4.8) [67]. Using culture-independent characterization of vaginal bacterial communities in a high-risk pregnant population, we show that the perceived benefit of lactobacilli dominance in pregnancy is species specific; $L$. crispatus is advantageous and associated with term delivery whereas $L$. iners is associated with increased risk of preterm delivery. Furthermore, $L$. iners is associated more specifically with a risk of early (<34 weeks) rather than late (34-37 weeks) preterm birth. High relative abundance of $L$. crispatus is highly specific for term birth, with a false positive rate (1 specificity) of just $3 \%$ in our population of women at high risk because of a previous preterm birth. In this population, second trimester dominance of L. iners carries a $67 \%$ detection rate (i.e., sensitivity) for preterm birth before 34 weeks; a screening sensitivity comparable to cervical length, the current and primary screening tool used for preterm birth surveillance [32,68]. Consistent with our findings, Petricevic and colleagues recently reported an over-representation of $L$. iners dominance in vaginal swab samples collected from 13 preterm births derived from a low-risk cohort of 111 pregnancies, and none of whom delivered before 33 weeks of gestation [25]. 


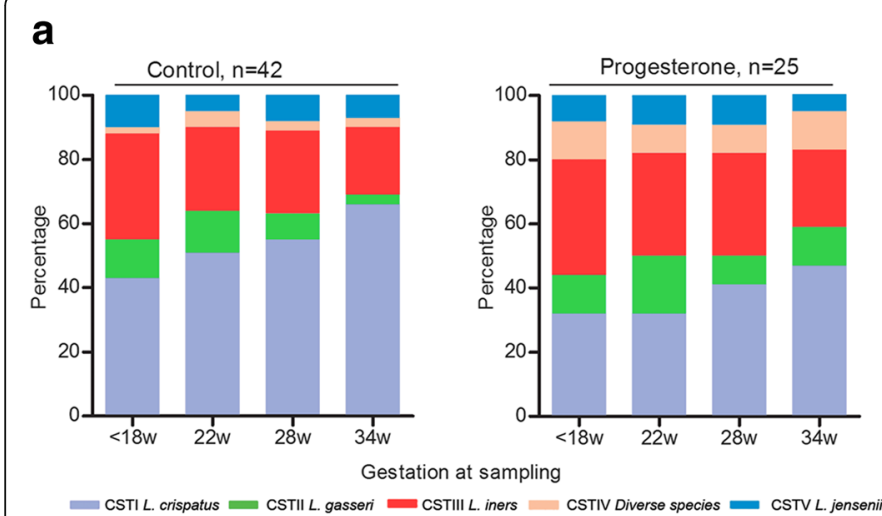

b

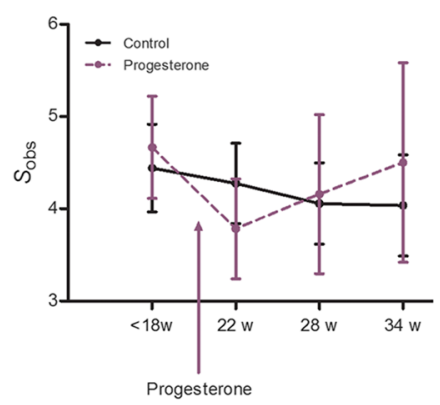

C

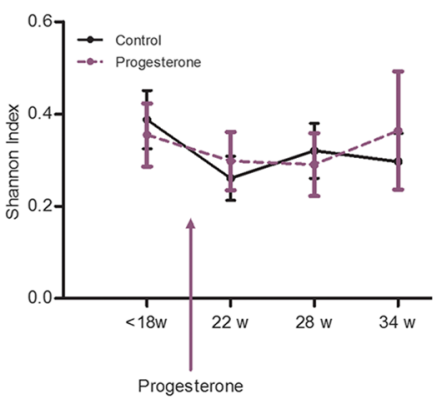

d

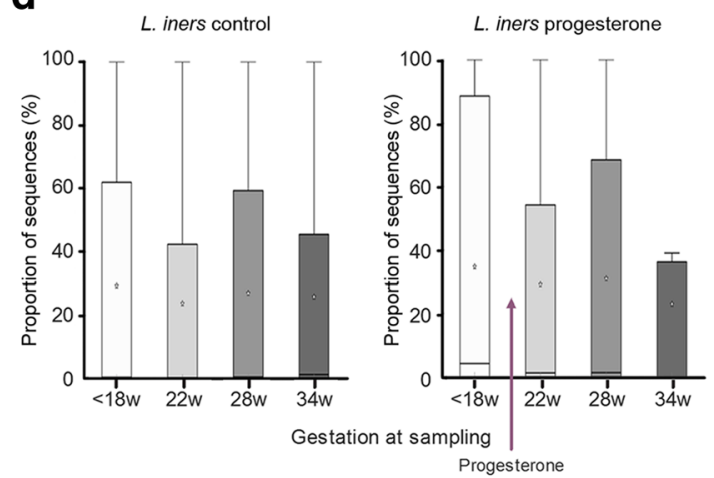

e

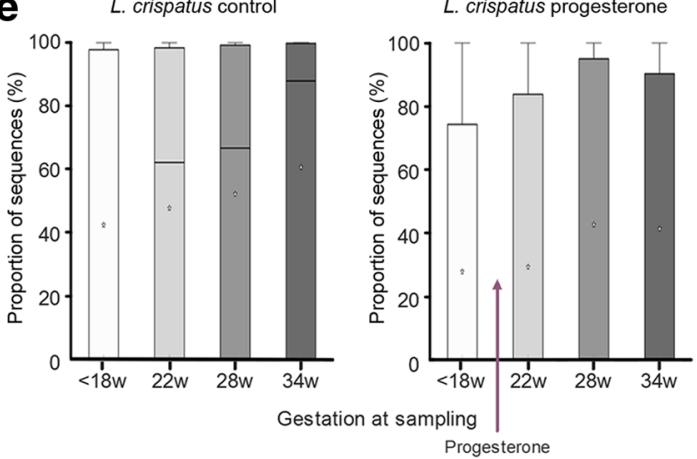

Fig. 2 Vaginal progesterone treatment does not alter structure of the vaginal microbiome. a Compared to controls $(n=42)$, progesterone supplementation $(n=25)$ had no significant impact upon microbial community profiles with advancing gestation. Similarly, no effect of progesterone treatment upon $\mathbf{b}$ the number of species observed or $\mathbf{c}$ the corresponding Shannon index of alpha diversity was observed (2-way ANOVA). Fewer women requiring progesterone had a L. crispatus dominated microbiome compared to controls (8/25, 32 vs. 18/42, 43\%, $P=0.4)$; however, progesterone treatment was associated with increased relative $L$. crispatus abundance with advancing gestation. Advancing gestational age from 18 to 34 weeks was not associated with a significant shift in mean relative abundance of $L$. iners (d) or $L$. crispatus (e) in either the controls or progesterone groups (Kruskal-Wallis, Dunn's multiple comparison)

However, this study was limited by the use of denaturing gradient gel electrophoresis (DGGE) for the characterization of only major Lactobacillus species and could not identify other pathobionts in the samples.

While our study reveals a clear relationship between relative abundance of vaginal Lactobacillus species and risk of subsequent preterm birth, our data indicate that Lactobacillus spp. depletion or vaginal dysbiosis in the second trimester does not appear to contribute to preterm birth risk. The role of early gestational vaginal dysbiosis in the pathology of preterm birth is controversial. In agreement with our findings, a recent longitudinal analysis of the vaginal microbiome by Romero and colleagues in 18 women experiencing preterm birth ( $<34$ weeks gestation) reported no association between preterm birth and vaginal microbial dysbiosis when compared to controls experiencing term delivery $(n=72)$ [24]. However, in their study, 95\% (17/18) of preterm birth samples and $86 \%$ of control samples were collected from African American women who exhibit a higher pregnant and non-pregnant background prevalence of vaginal dysbiosis (CST IV) [13, 24]. In contrast to these findings, Digiulio and co-workers [19] reported, in a small yet densely sampled cohort of women experiencing preterm birth $(n=15)$, which vaginal bacterial diversity does correlate with risk of preterm delivery [19]. The clinical relevance of these findings however are difficult to establish considering the small sample size and the heterogeneous nature of the cohort; only five women delivered preterm spontaneously and almost half delivered within 1 week of term dates $\left(>36\right.$ weeks ${ }^{+3 / 7}$ days $)$.

Our presented data provide some suggestion that vaginal microbiota in Black women may not play as an important contributory role to preterm birth pathogenesis as Caucasians and Asians. We did not however have sufficient power to demonstrate the significance of this, but this may be worth examining in future studies.

In our study, we also observed a high rate of CSTshifting in women with an L. iners-dominated microbiome in the second trimester compared to women with an $L$. crispatus-dominated microbiome. L. iners has been reported as an intermediary between lactobacilli 


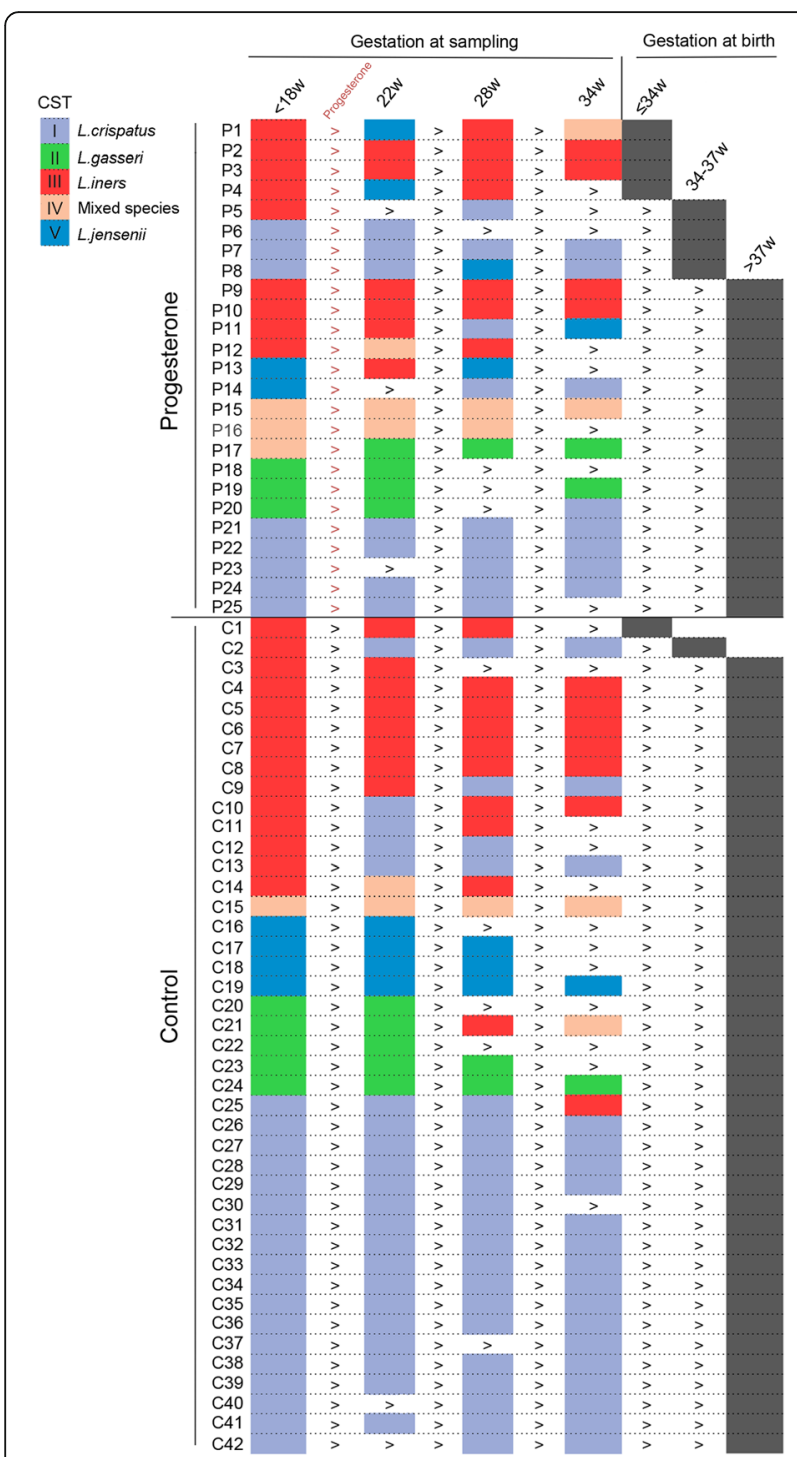

Fig. 3 Longitudinal profiling of community state types for progesterone $(n=25)$ and control groups $(n=42)$. Progesterone supplementation was commenced after the first sampling time point ( $<18$ weeks). Each longitudinal sample was assigned to a CST (Fig. 1a) as indicated by the color-coded rectangle and categorized as a function of delivery gestation

dominance and CST IV-associated states and is the predominant microbiome in peri-menopausal women as they transition through to postmenopausal dominance of anaerobic bacteria [16]. Interactions between $L$. iners and the maternal host likely provides a vaginal mucosal environment permissible to colonization by BVassociated pathogens, a setting in which it tolerates coexistence well $[69,70]$. Unlike other Lactobacillus species, $L$. iners also induces secretion of pro-inflammatory cytokines when human vaginal epithelial cells are observed in vitro, whereas $L$. crispatus does not $[71,72]$.
Other evidence for a role of bacterial dysbiosis in the pathology of preterm birth includes the long recognized association between bacterial vaginosis (BV) and increased risk of preterm birth; however, evidence suggests that screening and treating BV in pregnancy reduces preterm delivery in certain cohorts [73], but not in others [74]. We propose an alternate concept, which is that it is the presence of $L$. iners that promotes risk of early preterm birth, but because an $L$. iners-dominated vaginal microbiome has less stability, there is a tendency for transition to BV-associated CST-IV [69, 75]. Indeed, $L$. iners is the prominent vaginal species following antibiotic treatment for BV [76]. Older studies aimed at detecting BV, which could not differentiate Lactobacillus species and concluded that it was BV rather than species of Lactobacillus that conferred the risk.

Recent investigations into the protective role of Lactobacillus species in the context of reproductive health have revealed major species-specific differences in the capacity to prevent pathobiont colonization and viral infections [12, 72, 77, 78] that are driven largely by maternal host-bacterial metabolite interactions at the vaginal mucosal interface. For example, although lactic acid-producing bacteria including Lactobacillus spp. produce both the D- and L-lactic acid isomers [79], the chirality of the isomer has major functional implications. In women exhibiting a vaginal microbiome dominated by $L$. iners, an increased ratio of $L$ to D-lactic acid has previously been shown to promote expression of vaginal extracellular matrix metalloproteinase inducer (EMMPRIN) and the activation of matrix metalloproteinase- 8 (MMP8), which may subsequently modulate cervical integrity [80]. Conversely, no such relationship has been observed in women with vaginal microbial communities dominated by $L$. crispatus, which instead preferentially excretes high levels of D-lactic acid and greater overall levels of lactic acid than $L$. iners [80]. Apart from modulating local tissue inflammation, recent studies have also implicated lactate isomers in vaginal mucosal trapping mechanisms. High concentrations of D-lactic acid are associated with $L$. crispatus dominance and enhanced trapping of HIV-1 virions in cervico-vaginal mucosa whereas low concentrations of D-lactic acid associated with $L$. iners dominance permits comparatively rapid diffusion of virions through cervico-vaginal mucosa [77]. Collectively, these data suggest mechanisms by which $L$. iners dominance of vaginal microbial communities during pregnancy may lead to the modulation of local tissue inflammation and remodeling pathways and to disruption of chemical and mechanical mucosal barriers protective against ascending infection and increase the risk of preterm birth. Such mechanisms may account for the observed association between $L$. iners dominance and a short cervical length $(<25 \mathrm{~mm})$ seen in our study at 


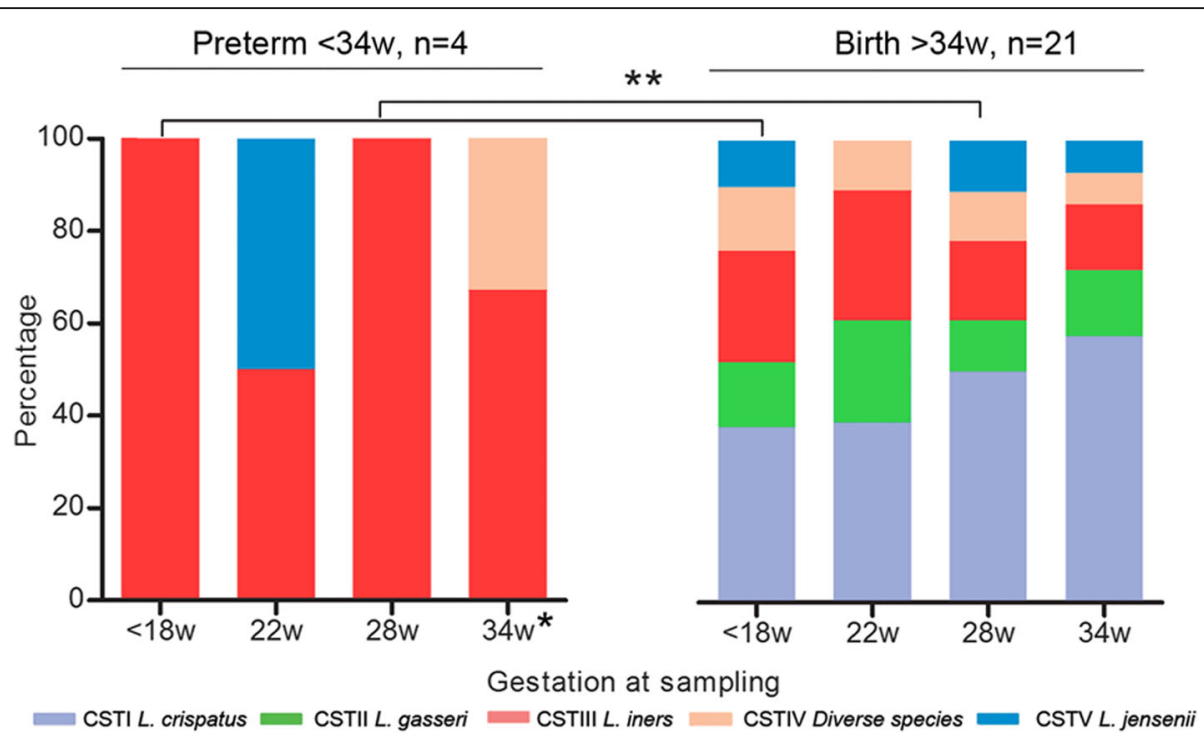

Fig. 4 Preterm birth, despite vaginal progesterone, is associated with L. iners dominance throughout pregnancy. Longitudinal sampling of 25 women receiving progesterone for a short cervix showed $L$. iners dominance was associated with all women who subsequently delivered preterm $<34^{+0}$ weeks $\left(n=4\right.$; ( ${ }^{* *} P<0.05$; Fisher's exact). Single asterisk indicates the delivery samples collected within 2 weeks of delivery between 28 and 34 weeks

16 weeks of gestation, which itself is highly specific for preterm birth [81].

Considering the potential pro-inflammatory roles played by $L$. iners in the vagina during pregnancy, we postulated that any associated poor pregnancy outcomes might be attenuated by the anti-inflammatory actions of progesterone $[45,82]$. However, in this study, no effect of vaginal progesterone therapy upon the frequency of vaginal community state structure was observed across pregnancy indicating that the mode of action of progesterone in the prevention of preterm birth is not through modulation of the vaginal microbiome. The data also show, however, that there is no detrimental effect upon the vaginal microbiome of either progesterone itself or of the daily vaginal insertion of a pessary.

A particular strength of our study is that we characterized the vaginal microbiome in a comparatively large patient cohort at high risk of preterm birth. This strength was demonstrated by a high spontaneous preterm birth rate $(n=34 / 161)$. The mean gestation at birth of $32^{+6}$ weeks within our preterm birth cohort, and a distribution of gestational ages ranging from 24 to 36 weeks, enabled the characterization of microbial profiles associated with both early $(<34$ weeks) and late (34 > 37 weeks) preterm birth, providing a broader observational base for microbial-host interactions in pregnancy. The primary limitation was the small number of women receiving progesterone $(n=25)$ and the lack of an equivalent control group with a short $\mathrm{CL}<25 \mathrm{~mm}$ not receiving any intervention or receiving a placebo. A short CL significantly increases subsequent preterm birth risk [33]; therefore, once detected, clinicians are ethically obliged to provide a preventative intervention such as progesterone. Consequently, a "placebo" intervention for a short cervix could not be included for study in this clinical study. As such, the control women are not true controls as their cervical lengths were all greater than $25 \mathrm{~mm}$ at entry. A further potential confounding factor was the impact of ethnicity of vaginal microbiota and gestation at birth, although we demonstrated this not to be significant in our cohort.

\section{Conclusions}

Our data indicate that specific Lactobacillus species have differing associations with outcome in pregnancies at high risk of preterm birth. Detection of vaginal microbial composition in the early second trimester may be used to stratify preterm birth risk; L. crispatus dominance is highly predictive of term birth, while high $L$. iners relative abundance is associated with increased risk of preterm birth and warrants heighted surveillance. Increased diversity of vaginal microbiota at 16 weeks of gestation is not associated with increased risk of preterm birth. The use of progesterone therapy for preterm birth prevention does not appear to adversely affect the relative abundance of vaginal Lactobacillus species or species diversity, indicating that progesterone's mode of action during pregnancy is likely not via modulation of vaginal microbial communities. Patients and clinicians who may be concerned about the "infection risk" associated with the use of vaginal pessaries during high-risk pregnancy can be reassured. 


\section{Additional files}

Additional file 1: Work flow of methodology for cross-sectional and longitudinal studies.

Additional file 2: Detailed methodology for statistical analyses. Additional file 3: Species read count data for cross-sectional cohort. Additional file 4: Patient metadata for cross-sectional cohort. Additional file 5: Species read count data for longitudinal cohort (progesterone treatment).

Additional file 6: Patient metadata for longitudinal cohort (progesterone treatment).

Additional file 7: Preterm birth does not associate with vaginal dysbiosis at 16 weeks of gestation. (A) Heatmap of ward hierarchical clustering of microbial genera from 161 women sampled at 16 weeks of gestation, classified according to subsequent gestation at delivery. Women delivering preterm both $<34^{+0}$ weeks $\left(n=18\right.$, red) and $34^{+0}$ to $36^{+6}$ weeks ( $n=16$, orange) had a predominantly Lactobacillus species-dominated vaginal microbiome, as did women experiencing term births $>37^{+0}$ weeks ( $n=127$, gray). (B) No correlation between richness (number of bacterial species observed; $S_{o b s}$ ) $(C)$, nor alpha diversity as measured using the Shannon index with gestation at birth was observed. (ns non-significant, 2-way ANOVA).

Additional file 8: Linear mixed-effects model of cross-sectional data assessing the correlation between CST, gestational age at sample, maternal age, and BMI on pregnancy outcome.

Additional file 9: Linear mixed-effects model assessing the impact of relative species abundance at 16 weeks on subsequent gestation at birth

Additional file 10: Distribution of CSTs as a function of ethnicity and gestation at birth in cross-sectional cohort.

Additional file 11: Gestational age at vaginal sampling in high-risk control and progesterone groups.

Additional file 12: Community state type classification of samples as a function of gestation at sampling: progesterone versus control groups.

Additional file 13: Comparison of mean L. iners and L. crispatus relative abundance in control $(n=42)$ versus progesterone groups $(n=25)$ and as a function of birth before and after 34 weeks. (A) Prior to progesterone intervention at $<18$-week sampling, women with a short $\mathrm{CL}<25 \mathrm{~mm}$ had greater relative abundance of $L$. iners compared to controls, and lower $L$. crispatus (B) although this did not reach significance. L. iners abundance declined in both control and progesterone groups towards 34 weeks of sampling while mean L. crispatus abundance increased (ANOVA, K-W, Dunn's multiple comparison). Inclusive of control and progesterone groups, preterm birth $<34$ weeks was associated with higher mean $L$. iners abundance at longitudinal sampling ( $C ; P<0.05)$, and lower mean $L$. crispatus abundance (D; $P<0.001)$ than deliveries $>34$ weeks, at matched gestational age at sampling throughout follow-up (Welch's $t$ test)

Additional file 14: Mixed-effects model assessing the impact of progesterone treatment on CST profile at longitudinal sampling, incorporating potential contributing confounders (gestational age at sample, maternal age, BMI, and ethnicity).

Additional file 15: Mixed-effects model comparing relative species abundance in control and progesterone groups.

\footnotetext{
Abbreviations

bp: Base pairs; BV: Bacterial vaginosis; Cl: Confidence interval; CL: Cervical length; CST: Community state type; DDGE: Denaturing gradient gel electrophoresis; EMMPRIN: Extracellular matrix metalloproteinase inducer; HCA: Hierarchical cluster analysis; HIV: Human immunodeficiency virus; MMP: Metalloproteinase; NHS: National Health Service; NPV: Negative predictive value; OD: Omne in die (once per day); OR: Odds ratio; PPV: Positive predictive value; RDP: Ribosomal database project; REC: Research ethics committee; rRNA: Ribosomal ribonucleic acid; SD: Standard deviation; STAMP: Statistical Analysis of Metagenomic Profiles; TVS: Transvaginal scan
}

\section{Acknowledgements}

We thank all participants of the study and members of Women's Health Research Centre, Imperial College Health NHS.

\section{Funding}

This work was supported by the National Institute for Health Research (NIHR) Comprehensive Biomedical Research Centre at Imperial College London (Grant Ref P45272) and by the Genesis Research Trust (Grant Ref P51389). DAM is supported by a Career Development Award from the Medical Research Council (MR/L009226/1).

\section{Availability of data and materials}

The sequence datasets and relevant metadata supporting the conclusions of this study can be obtained at the European Nucleotide Archive's (ENA) Sequence Read Archive (SRA) (accession number PRJEB11895 and PRJEB12577). Further details of all statistical analyses performed in this manuscript are provided in Additional file 2. Species-level read count data used for these analyses along with the relevant metadata are provided in Additional files 3, 4, 5, and 6 .

\section{Authors' contributions}

LMK, PRB, and DAM conceived and designed the experiments. LMK and YSL collected samples and performed experiments. LMK, JRM, AS, SC, and DAM performed the data analysis and generated the figures and tables. LMK, PRB, and DAM wrote the first draft of the manuscript. LMK, PRB, YSL, JRM, AS, SC, EH, JKN, TGT, and DAM critically reviewed the data and the manuscript. All authors read and approved the final manuscript.

\section{Competing interests}

The views expressed in the submitted article are of the authors and not an official position of the institutions or funders. The authors declare that they have no competing interests.

\section{Consent for publication}

Not applicable.

\section{Ethics approval and consent to participate}

The study was approved by NHS National Research Ethics Service (NRES) Committee London - City and East (REC 12/LO/2003), and all participants provided written, informed consent at enrolment.

\section{Author details}

${ }^{1}$ Imperial College Parturition Research Group, Division of the Institute of Reproductive and Developmental Biology, Department of Surgery and Cancer, Faculty of Medicine, Imperial College London, Hammersmith Campus, London W12 0NN, UK. Q Queen Charlotte's Hospital, Imperial College Healthcare NHS Trust, London, UK. ${ }^{3}$ Department of Obstetrics and Gynaecology, St Mary's Hospital, Imperial College Healthcare NHS Trust, London, UK. ${ }^{4}$ Centre for Digestive and Gut Health, Department of Surgery and Cancer and the Institute of Global Health Innovation, Faculty of Medicine, Imperial College London, London, UK. ${ }^{5}$ School of Biosciences, Cardiff University, Cardiff, UK. ${ }^{6}$ Division of Computational Systems Medicine, Department of Surgery and Cancer, Faculty of Medicine, Imperial College London, London, UK.

Received: 26 July 2016 Accepted: 15 December 2016 Published online: 19 January 2017

References

1. Causes of child mortality [http://www.who.int/gho/child_health/mortality/ causes/en/]. Accessed 7 July 2016.

2. McCormick MC, Litt JS, Smith VC, Zupancic JA. Prematurity: an overview and public health implications. Annu Rev Public Health. 2011;32:367-79.

3. Goldenberg RL, Culhane JF, lams JD, Romero R. Epidemiology and causes of preterm birth. Lancet. 2008:371(9606):75-84.

4. Liu L, Oza S, Hogan D, Perin J, Rudan I, Lawn JE, Cousens S, Mathers C, Black RE. Global, regional, and national causes of child mortality in 2000-13, with projections to inform post-2015 priorities: an updated systematic analysis. Lancet. 2015;385(9966):430-40.

5. Romero R, Dey SK, Fisher SJ. Preterm labor: one syndrome, many causes. Science. 2014;345(6198):760-5. 
6. Eckburg PB, Bik EM, Bernstein CN, Purdom E, Dethlefsen L, Sargent M, Gill $\mathrm{SR}$, Nelson KE, Relman DA. Diversity of the human intestinal microbial flora. Science. 2005;308(5728):1635-8.

7. Turnbaugh PJ, Ley RE, Mahowald MA, Magrini V, Mardis ER, Gordon Jl. An obesity-associated gut microbiome with increased capacity for energy harvest. Nature. 2006:444(7122):1027-31

8. Maclntyre DA, Chandiramani M, Lee YS, Kindinger L, Smith A, Angelopoulos $\mathrm{N}$, Lehne B, Arulkumaran S, Brown R, Teoh TG, et al. The vaginal microbiome during pregnancy and the postpartum period in a European population. Sci Rep. 2015;5:8988.

9. Romero R, Hassan SS, Gajer P, Tarca AL, Fadrosh DW, Nikita L, Galuppi M, Lamont RF, Chaemsaithong P, Miranda J, et al. The composition and stability of the vaginal microbiota of normal pregnant women is different from that of non-pregnant women. Microbiome. 2014;2(1):4.

10. Reid G, Younes JA, Van der Mei HC, Gloor GB, Knight R, Busscher HJ. Microbiota restoration: natural and supplemented recovery of human microbial communities. Nat Rev Microbiol. 2011:9(1):27-38.

11. van de Wijgert $J H$, Jespers $\mathrm{V}$. Incorporating microbiota data into epidemiologic models: examples from vaginal microbiota research. Ann Epidemiol. 2016;26(5):360-5.

12. Borgdorff $H$, Tsivtsivadze $E$, Verhelst $R$, Marzorati M, Jurriaans S, Ndayisaba GF, Schuren FH, van de Wijgert JH. Lactobacillus-dominated cervicovaginal microbiota associated with reduced HIV/STI prevalence and genital HIV viral load in African women. ISME J. 2014;8(9):1781-93.

13. Ravel J, Gajer P, Abdo Z, Schneider GM, Koenig SS, McCulle SL, Karlebach S, Gorle R, Russell J, Tacket CO, et al. Vaginal microbiome of reproductive-age women. Proc Natl Acad Sci U S A. 2011;108 Suppl 1:4680-7.

14. Chaban B, Links MG, Jayaprakash TP, Wagner EC, Bourque DK, Lohn Z, Albert AY, van Schalkwyk J, Reid G, Hemmingsen SM, et al. Characterization of the vaginal microbiota of healthy Canadian women through the menstrual cycle. Microbiome. 2014;2:23.

15. van de Wijgert JHHM, Verwijs MC, Turner AN, Morrison CS. Hormonal contraception decreases bacterial vaginosis but oral contraception may increase candidiasis: implications for HIV transmission. Aids. 2013;27(13):2141-53.

16. Brotman RM, Shardell MD, Gajer P, Fadrosh D, Chang K, Silver MI, Viscidi RP, Burke AE, Ravel J, Gravitt PE. Association between the vaginal microbiota, menopause status, and signs of vulvovaginal atrophy. Menopause. 2014;21(5):450-8.

17. Shen J, Song N, Williams CJ, Brown CJ, Yan Z, Xu C, Forney LJ. Effects of low dose estrogen therapy on the vaginal microbiomes of women with atrophic vaginitis. Sci Rep. 2016;6:24380.

18. Spear GT, French AL, Gillbert D, Zariffard MR, Mirmonsef $P$, Sullivan $T H$, Spear WW, Landay A, Micci S, Lee BH, et al. Human alpha-amylase present in lower-genital-tract mucosal fluid processes glycogen to support vaginal colonization by Lactobacillus. J Infect Dis. 2014;210(7):1019-28.

19. DiGiulio DB, Callahan BJ, McMurdie PJ, Costello EK, Lyell DJ, Robaczewska A, Sun CL, Goltsman DS, Wong RJ, Shaw G, et al. Temporal and spatial variation of the human microbiota during pregnancy. Proc Natl Acad Sci U S A. 2015;112(35):11060-5.

20. Leitich $\mathrm{H}$, Kiss $\mathrm{H}$. Asymptomatic bacterial vaginosis and intermediate flora as risk factors for adverse pregnancy outcome. Best Pract Res Clin Obstet Gynaecol. 2007;21(3):375-90.

21. Chandiramani M, Bennett PR, Brown R, Lee YS, MacIntyre DA. Vaginal microbiome-pregnant host interactions determine a significant proportion of preterm labour. Fetal Matern Med Rev. 2014;25(1):73-8.

22. Merrifield CA, Lewis MC, Berger B, Cloarec O, Heinzmann SS, Charton F, Krause L, Levin NS, Duncker S, Mercenier A, et al. Neonatal environment exerts a sustained influence on the development of the intestinal microbiota and metabolic phenotype. ISME J. 2015.

23. Dominguez-Bello MG, Costello EK, Contreras M, Magris M, Hidalgo G, Fiere $\mathrm{N}$, Knight R. Delivery mode shapes the acquisition and structure of the initial microbiota across multiple body habitats in newborns. Proc Natl Acad Sci U S A. 2010;107(26):11971-5.

24. Romero R, Hassan SS, Gajer P, Tarca AL, Fadrosh DW, Bieda J, Chaemsaithong P, Miranda J, Chaiworapongsa T, Ravel J. The vaginal microbiota of pregnant women who subsequently have spontaneous preterm labor and delivery and those with a normal delivery at term. Microbiome. 2014;2:18

25. Petricevic L, Domig KJ, Nierscher FJ, Sandhofer MJ, Fidesser M, Krondorfer I, Husslein P, Kneifel W, Kiss H. Characterisation of the vaginal Lactobacillus microbiota associated with preterm delivery. Sci Rep. 2014;4:5136.
26. Tamrakar R, Yamada T, Furuta I, Cho K, Morikawa M, Yamada H, Sakuragi N, Minakami H. Association between Lactobacillus species and bacterial vaginosis-related bacteria, and bacterial vaginosis scores in pregnant Japanese women. BMC Infect Dis. 2007;7:128.

27. Srinivasan S, Hoffman NG, Morgan MT, Matsen FA, Fiedler TL, Hall RW, Ross FJ, McCoy CO, Bumgarner R, Marrazzo JM, et al. Bacterial communities in women with bacterial vaginosis: high resolution phylogenetic analyses reveal relationships of microbiota to clinical criteria. PLoS One. 2012; $7(6)$, e37818

28. Africa CW, Nel J, Stemmet M. Anaerobes and bacterial vaginosis in pregnancy: virulence factors contributing to vaginal colonisation. Int J Environ Res Public Health. 2014;11(7):6979-7000.

29. Word RA, Li XH, Hnat M, Carrick K. Dynamics of cervical remodeling during pregnancy and parturition: mechanisms and current concepts. Semin Reprod Med. 2007;25(1):69-79.

30. Guzeloglu-Kayisli O, Kayisli UA, Semerci N, Basar M, Buchwalder LF, Buhimschi CS, Buhimschi IA, Arcuri F, Larsen K, Huang JS, et al. Mechanisms of chorioamnionitis-associated preterm birth: interleukin-1 beta inhibits progesterone receptor expression in decidual cells. J Pathol. 2015.

31. Ekman-Ordeberg G, Dubicke A. Preterm cervical ripening in humans. Facts Views Vis Obgyn. 2012;4(4):245-53.

32. Grimes-Dennis J, Berghella V. Cervical length and prediction of preterm delivery. Curr Opin Obstet Gynecol. 2007;19(2):191-5.

33. lams JD, Goldenberg RL, Meis PJ, Mercer BM, Moawad A, Das A, Thom E, McNellis D, Copper RL, Johnson F, et al. The length of the cervix and the risk of spontaneous premature delivery. National Institute of Child Health and Human Development Maternal Fetal Medicine Unit Network. N Engl J Med. 1996;334(9):567-72

34. lams JD. Prevention of preterm parturition. N Engl J Med. 2014;370(19):1861.

35. Romero R, Nicolaides K, Conde-Agudelo A, Tabor A, O'Brien JM, Cetingoz E, Da Fonseca E, Creasy GW, Klein K, Rode L, et al. Vaginal progesterone in women with an asymptomatic sonographic short cervix in the midtrimester decreases preterm delivery and neonatal morbidity: a systematic review and metaanalysis of individual patient data. Am J Obstet Gynecol. 2012;206(2): 124. e121-119.

36. Alfirevic Z, Stampalija T, Roberts D, Jorgensen AL. Cervical stitch (cerclage) for preventing preterm birth in singleton pregnancy. Cochrane Database Syst Rev. 2012:4, CD008991.

37. Kindinger LM, MacIntyre DA, Lee YS, Marchesi JR, Smith A, McDonald JA, Terzidou V, Cook JR, Lees C, Israfil-Bayli F, et al. Relationship between vaginal microbial dysbiosis, inflammation, and pregnancy outcomes in cervical cerclage. Sci Transl Med. 2016:8(350):350ra. 102.

38. Resseguie LJ, Hick JF, Bruen JA, Noller KL, O'Fallon WM, Kurland LT. Congenital malformations among offspring exposed in utero to progestins, Olmsted County, Minnesota, 1936-1974. Fertil Steril. 1985:43(4):514-9.

39. Northen AT, Norman GS, Anderson K, Moseley L, Divito M, Cotroneo M, Swain M, Bousleiman S, Johnson F, Dorman K, et al. Follow-up of children exposed in utero to 17 alpha-hydroxyprogesterone caproate compared with placebo. Obstet Gynecol. 2007;110(4):865-72

40. Anderson L, Martin W, Higgins C, Nelson SM, Norman JE. The effect of progesterone on myometrial contractility, potassium channels, and tocolytic efficacy. Reprod Sci. 2009;16(11):1052-61.

41. Hardy DB, Janowski BA, Corey DR, Mendelson CR. Progesterone receptor plays a major antiinflammatory role in human myometrial cells by antagonism of nuclear factor-kappaB activation of cyclooxygenase 2 expression. Mol Endocrinol. 2006;20(11):2724-33.

42. Loudon JA, Elliott CL, Hills F, Bennett PR. Progesterone represses interleukin8 and cyclo-oxygenase-2 in human lower segment fibroblast cells and amnion epithelial cells. Biol Reprod. 2003;69(1):331-7.

43. Tan H, Yi L, Rote NS, Hurd WW, Mesiano S. Progesterone receptor-A and -B have opposite effects on proinflammatory gene expression in human myometrial cells: implications for progesterone actions in human pregnancy and parturition. J Clin Endocrinol Metab. 2012;97(5):E719-30.

44. Carbonne B, Dallot E, Haddad B, Ferré F, Cabrol D. Effects of progesterone on prostaglandin $E(2)$-induced changes in glycosaminoglycan synthesis by human cervical fibroblasts in culture. Mol Hum Reprod. 2000;6(7):661-4.

45. Nold C, Maubert M, Anton L, Yellon S, Elovitz MA. Prevention of preterm birth by progestational agents: what are the molecular mechanisms? Am J Obstet Gynecol. 2013;208(3):223. e221-227.

46. Yellon SM, Dobyns AE, Beck HL, Kurtzman JT, Garfield RE, Kirby MA. Loss of progesterone receptor-mediated actions induce preterm cellular and 
structural remodeling of the cervix and premature birth. PLoS One. 2013; 8(12), e81340.

47. Facchinetti F, Paganelli S, Comitini G, Dante G, Volpe A. Cervical length changes during preterm cervical ripening: effects of 17-alphahydroxyprogesterone caproate. Am J Obstet Gynecol. 2007;196(5):453. e451454; discussion 421.

48. Hassan S, Romero R, Vidyadhari D, Fusey S, Baxter J, Khandelwal M, Vijayaraghavan J, Trivedi Y, Soma-Pillay P, Sambarey P. Vaginal progesterone reduces the rate of preterm birth in women with a sonographic short cervix: a multicenter, randomized, double-blind, placebo-controlled trial. Ultrasound Obstet Gynecol. 2011;38(1):18-31.

49. Fonseca EB, Celik E, Parra M, Singh M, Nicolaides KH, Group FMFSTS. Progesterone and the risk of preterm birth among women with a short cervix. N Engl J Med. 2007;357(5):462-9.

50. O'Brien JM, Adair CD, Lewis DF, Hall DR, Defranco EA, Fusey S, Soma-Pillay P, Porter $\mathrm{K}$, How H, Schackis R, et al. Progesterone vaginal gel for the reduction of recurrent preterm birth: primary results from a randomized, double-blind, placebo-controlled trial. Ultrasound Obstet Gynecol. 2007;30(5):687-96.

51. van Os MA, van der Ven AJ, Kleinrouweler CE, Schuit E, Kazemier BM, Verhoeven CJ, de Miranda E, van Wassenaer-Leemhuis AG, Sikkema JM, Woiski MD, et al. Preventing preterm birth with progesterone in women with a short cervical length from a low-risk population: a multicenter double-blind placebo-controlled randomized trial. Am J Perinatol. 2015; 32(10):993-1000

52. Borgdorff H, Verwijs MC, Wit FW, Tsivtsivadze E, Ndayisaba GF, Verhelst $R$, Schuren $\mathrm{FH}$, van de Wijgert $\mathrm{JH}$. The impact of hormonal contraception and pregnancy on sexually transmitted infections and on cervicovaginal microbiota in african sex workers. Sex Transm Dis. 2015;42(3):143-52.

53. Ralph LJ, McCoy SI, Shiu K, Padian NS. Hormonal contraceptive use and women's risk of HIV acquisition: a meta-analysis of observational studies. Lancet Infect Dis. 2015;15(2):181-9.

54. Blish CA, Baeten JM. Hormonal contraception and HIV-1 transmission. Am J Reprod Immunol. 2011;65(3):302-7.

55. Sundquist A, Bigdeli S, Jalili R, Druzin ML, Waller S, Pullen KM, El-Sayed YY, Taslimi MM, Batzoglou S, Ronaghi M. Bacterial flora-typing with targeted, chip-based pyrosequencing. BMC Microbiol. 2007;7:108

56. Kozich JJ, Westcott SL, Baxter NT, Highlander SK, Schloss PD. Development of a dual-index sequencing strategy and curation pipeline for analyzing amplicon sequence data on the MiSeq Illumina sequencing platform. Appl Environ Microbiol. 2013;79(17):5112-20.

57. Wang Q, Garrity GM, Tiedje JM, Cole JR. Naive Bayesian classifier for rapid assignment of rRNA sequences into the new bacterial taxonomy. Appl Environ Microbiol. 2007;73(16):5261-7.

58. Edgar RC. Search and clustering orders of magnitude faster than BLAST. Bioinformatics. 2010;26(19):2460-1.

59. Schloss PD, Westcott SL, Ryabin T, Hall JR, Hartmann M, Hollister EB, Lesniewski RA, Oakley BB, Parks DH, Robinson CJ, et al. Introducing mothur: open-source, platform-independent, community-supported software for describing and comparing microbial communities. Appl Environ Microbiol. 2009;75(23):7537-41.

60. Parks DH, Beiko RG. Identifying biologically relevant differences between metagenomic communities. Bioinformatics. 2010;26(6):715-21.

61. Breslow N. Covariance analysis of censored survival data. Biometrics. 1974 30(1):89-99.

62. Benjamini $Y$, Hochberg $Y$. Controlling the false discovery rate: a practical and powerful approach to multiple testing. J R Stat Soc Ser B Methodol. 1995;57(1):289-300.

63. Donders GG, Bosmans E, Dekeersmaecker A, Vereecken A, Van Bulck B, Spitz B. Pathogenesis of abnormal vaginal bacterial flora. Am J Obstet Gynecol. 2000;182(4):872-8.

64. Gupta K, Stapleton AE, Hooton TM, Roberts PL, Fennell CL, Stamm WE. Inverse association of $\mathrm{H} 2 \mathrm{O} 2$-producing lactobacilli and vaginal Escherichia coli colonization in women with recurrent urinary tract infections. J Infect Dis. 1998;178(2):446-50.

65. Hillier SL, Krohn MA, Rabe LK, Klebanoff SJ, Eschenbach DA. The normal vaginal flora, $\mathrm{H} 2 \mathrm{O} 2$-producing lactobacilli, and bacterial vaginosis in pregnant women. Clin Infect Dis. 1993;16 Suppl 4:S273-81.

66. Martius J, Krohn MA, Hillier SL, Stamm WE, Holmes KK, Eschenbach DA. Relationships of vaginal Lactobacillus species, cervical Chlamydia trachomatis, and bacterial vaginosis to preterm birth. Obstet Gynecol. 1988; 71(1):89-95.
67. Donders GG, Van Calsteren K, Bellen G, Reybrouck R, Van den Bosch T, Riphagen I, Van Lierde S. Predictive value for preterm birth of abnormal vaginal flora, bacterial vaginosis and aerobic vaginitis during the first trimester of pregnancy. BJOG. 2009;116(10):1315-24.

68. Berghella V, Bega G, Tolosa JE, Berghella M. Ultrasound assessment of the cervix. Clin Obstet Gynecol. 2003;46(4):947-62.

69. Rampersaud R, Planet PJ, Randis TM, Kulkarni R, Aguilar JL, Lehrer RI, Ratner AJ. Inerolysin, a cholesterol-dependent cytolysin produced by Lactobacillus iners. J Bacteriol. 2011;193(5):1034-41.

70. Macklaim JM, Fernandes AD, Di Bella JM, Hammond JA, Reid G, Gloor GB. Comparative meta-RNA-seg of the vaginal microbiota and differential expression by Lactobacillus iners in health and dysbiosis. Microbiome. 2013;1(1):12.

71. Doerflinger SY, Throop AL, Herbst-Kralovetz MM. Bacteria in the vaginal microbiome alter the innate immune response and barrier properties of the human vaginal epithelia in a species-specific manner. J Infect Dis. 2014;209(12):1989-99.

72. Anahtar MN, Byrne EH, Doherty KE, Bowman BA, Yamamoto HS, Soumillon M, Padavattan N, Ismail N, Moodley A, Sabatini ME, et al. Cervicovaginal bacteria are a major modulator of host inflammatory responses in the female genital tract. Immunity. 2015;42(5):965-76.

73. Joergensen JS, Kjaer Weile LK, Lamont RF. The early use of appropriate prophylactic antibiotics in susceptible women for the prevention of preterm birth of infectious etiology. Expert Opin Pharmacother. 2014;15(15):2173-91.

74. Guaschino S, De Seta F, Piccoli M, Maso G, Alberico S. Aetiology of preterm labour: bacterial vaginosis. BJOG. 2006;113 Suppl 3:46-51.

75. Verstraelen H, Verhelst R, Claeys G, De Backer E, Temmerman M, Vaneechoutte M. Longitudinal analysis of the vaginal microflora in pregnancy suggests that L. crispatus promotes the stability of the normal vaginal microflora and that $\mathrm{L}$. gasseri and/or L. iners are more conducive to the occurrence of abnormal vaginal microflora. BMC Microbiol. 2009;9:116.

76. Ferris MJ, Norori J, Zozaya-Hinchliffe M, Martin DH. Cultivation-independent analysis of changes in bacterial vaginosis flora following metronidazole treatment. J Clin Microbiol. 2007;45(3):1016-8.

77. Nunn KL, Wang YY, Harit D, Humphrys MS, Ma B, Cone R, Ravel J, Lai SK. Enhanced trapping of HIV-1 by human cervicovaginal mucus is associated with Lactobacillus crispatus-dominant microbiota. MBio. 2015 6(5):e01084-01015.

78. Brotman RM, Shardell MD, Gajer P, Tracy JK, Zenilman JM, Ravel J, Gravitt PE. Interplay between the temporal dynamics of the vaginal microbiota and human papillomavirus detection. J Infect Dis. 2014;210(11):1723-33.

79. Linhares IM, Summers PR, Larsen B, Giraldo PC, Witkin SS. Contemporary perspectives on vaginal pH and lactobacilli. Am J Obstet Gynecol. 2011; 204(2):120. e121-125.

80. Witkin SS, Mendes-Soares H, Linhares IM, Jayaram A, Ledger WJ, Forney LJ. Influence of vaginal bacteria and D- and L-lactic acid isomers on vaginal extracellular matrix metalloproteinase inducer: implications for protection against upper genital tract infections. MBio. 2013;4(4):e00460-13.

81. Berghella V, Roman A, Daskalakis C, Ness A, Baxter JK. Gestational age at cervical length measurement and incidence of preterm birth. Obstet Gynecol. 2007;110(2 Pt 1):311-7.

82. Gotkin JL, Celver J, McNutt P, Shields AD, Howard BC, Paonessa DJ, Napolitano PG. Progesterone reduces lipopolysaccharide induced interleukin-6 secretion in fetoplacental chorionic arteries, fractionated cord blood, and maternal mononuclear cells. Am J Obstet Gynecol. 2006:195(4):1015-9. 